\title{
Thermodynamic properties of the bubble growth process in a pool boiling of water-ethanol mixture two-component system
}

https://doi.org/10.1515/chem-2019-0010

received June 21, 2017; accepted September 7, 2018.

\begin{abstract}
Saturated pool boiling in a two-component water-ethanol solution was studied at a pressure of one atmosphere in a horizontal stainless steel cylinder. Solutions with volumes of $3 \%, 7 \%$, and $12 \%$ of waterethanol solution were examined at a heat flux of 1.8 to 60 $\mathrm{kW} / \mathrm{m}^{2}$. Videos and photos were analyzed and changes in bubble diameter, growth, and departure parameters were recorded. The results showed that the bubble departure diameters increased with increasing heat flux, but diameters decrease with increasing ethanol mass fraction. The experimental data are evaluated with two models of Alavi Fazel and Hamzehkhani's model, have better fitting with Hamzehkhani’s model.
\end{abstract}

Keywords: Pool boiling; bubble growth; heat transfer; bubble departure \& diameter.

\section{Introduction}

Nuclear boiling is an application of heat transfer that, as the subject of many studies, has led to many empirical results. Nowadays, many researchers in various fields, including petroleum, petrochemical, nuclear power, and so on, have focused on the boiling phenomenon due to a significant increase in the heat transfer coefficient [1]. Most energy conversion systems and heat exchangers use boiling heat transfer to maximize efficiency. Boiling is a common issue in complex engineering problems,

\footnotetext{
*Corresponding author: Leila Mahdavian, Department of Chemistry, Doroud Branch, Islamic Azad University, P.O. Box: 133. Doroud. Iran, E-mail: Mahdavian_leila@yahoo.com; Mahdavian@iau-doroud.ac.ir Mohammad Sattari: Department of Chemistry, Doroud Branch, Islamic Azad University, P.O. Box: 133. Doroud. Iran
}

especially when in situations involving the transfer of heavy heat loads. A key problem in boiling is bubble dynamics, including bubble departure diameters, density of sources of bubble production per unit area, and bubble generation frequency [2]. More accurate understanding and modeling of the boiling process requires modeling of the sub-processes [3].

The process of bubble formation, growth, and movement in the boiling process significantly increases the boiling heat transfer coefficient compared to the convection mechanism without a phase change [4]. Studies of bubble dynamics during nuclear pool boiling reduce the computational cost. Bubble dynamics in pool boiling was extensively studied by Lord Rayleigh as he considered the sound created in the kettle of boiling water [5]. Bubble formation occurs when the surface temperature $\left(T_{w}\right)$ is higher than the temperature of liquid at a pressure of saturation $\left(\mathrm{T}_{\mathrm{sat}}\right)$ and heat is thereby transferred from the solid to liquid. The resulting heat flux depends on the temperature difference between the surface and the saturated liquid. The liquid is stagnant (the flow of liquid is zero) at pool boiling and movement adjacent to the solid surface is caused by the free convection in the growth of the bubble. Increasing heat flux activates more nucleation sites resulting in elevated bubble movement and the emergence of individual bubbles [6,7]. With a further increase in the heat flux, the bubbles appear as continuous flows or bubble columns. Further increases in the heat flux prevent the liquid from being heated because the heating surface becomes completely covered with steam. The increased surface temperature disperses the applied heat flux and the vapor layers act as a resistance [8]. The departure point of nuclear boiling is attained by increasing the flux to a point referred to as the critical heat flux.

The saturated pool boiling in a two-component water-ethanol solution was studied in a stainless steel horizontal cylinder at a pressure of one atmosphere. 

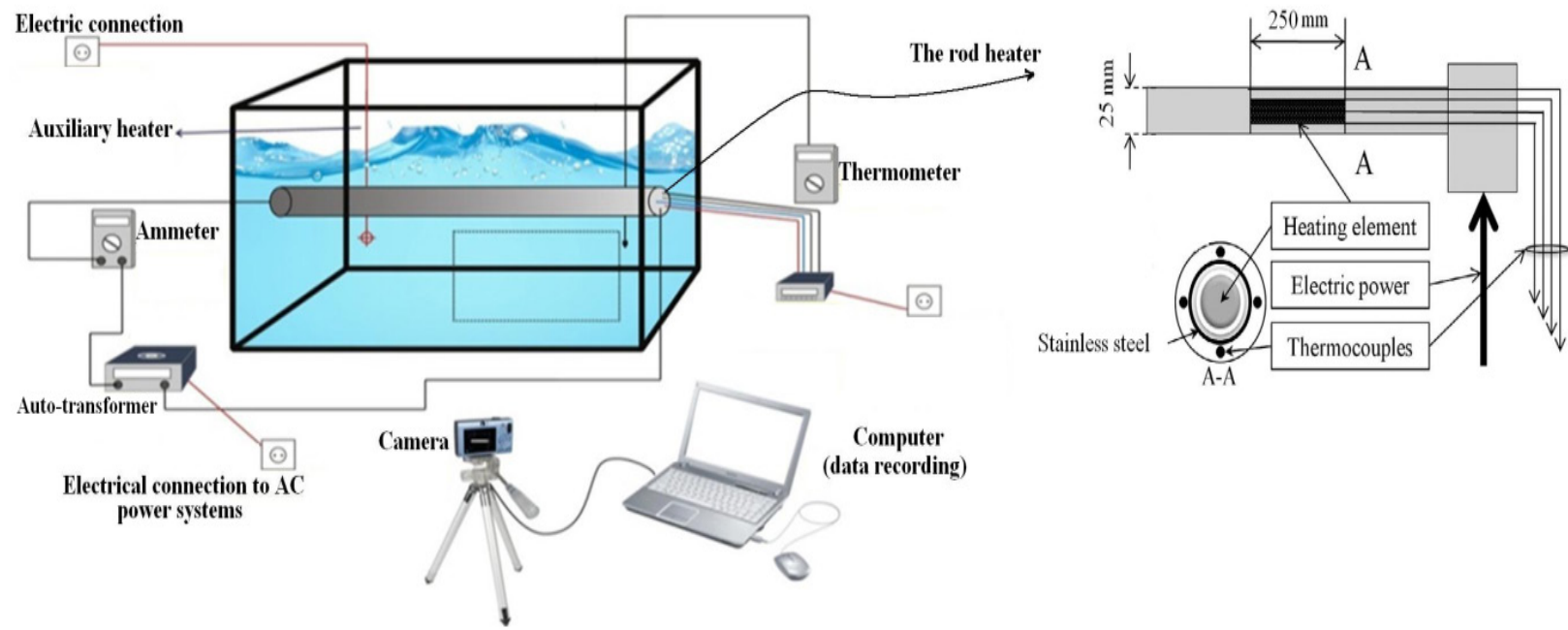

Figure 1: Overview of the pool boiling heat transfer device.

Bubble growth was predicted after examining the impacts of concentration, volume, heat flux, and a comparison between experimental results and theoretical models.

\section{Experimental methods}

All chemicals used in this study are from Merck Co., Germany.

\subsection{Device preparation}

The pool boiling heat transfer device, known as the Goren flow measuring device, is one of the most common and the most suitable devices for measuring the boiling heat transfer coefficient. The device has a central rod heater section consisting of a cylinder of stainless steel 316, which has an electrical conductivity of $0.75 \mathrm{~m} \mathrm{~W}^{-1} \mathrm{~mm}^{-2}$, low thermal conductivity $\left(15 \mathrm{~W} \cdot \mathrm{m}^{-1} \cdot \mathrm{K}^{-1}\right)$, and significant corrosion resistance. The rod heater length and diameter were 250 and $25 \mathrm{~mm}$, respectively, with four holes (50 $\mathrm{mm}$ in depth) in its cross-section for the placement of thermocouple sensors using silicon paste. An auto-transformer (power source with an electrical potential between zero and 300 volts) applied a heat flux in the range of 30 to $240 \mathrm{~V}$. The boiling vessel is made of tempered glass to allow boiling observation and recording. The glass is resistant to high temperatures up to approximately $550^{\circ} \mathrm{C}$ has dimensions of $151 \times 244 \times 230 \mathrm{~mm}$. The tests were performed in distilled water at a heat flux of 1800 to $60000 \mathrm{~W} / \mathrm{m}^{2}$. During pool boiling, films and photos were taken by a video camera (Imaging System) at 1200 frames for each heat flux.

The instrumentation consists of a thermocouple (K-type in the range of 0 to $700^{\circ} \mathrm{C}$ ), a temperature display, and an ammeter (Multimeter, 0.1A precision). After each test, the data were recorded and processed. Figure 1 shows the arrangement of the equipment.

In this experiment, the test container was filled to a certain volume $\left(7 \times 10^{-3} \mathrm{~m}^{3}\right)$ of solution with the intended ethanol:water ratio, and four thermocouple sensors were installed on the cylinder body. The pre-heating heater was turned on until the solution reached the saturation temperature. The solution was kept at the saturation temperature until all air bubbles were removed from the liquid phase. After the system reached steady state, the voltage was changed systematically, and resulting data were recorded.

Physical properties of the solution used, including vapor and liquid phase densities, surface tension, viscosity, specific heat capacity, enthalpy of vaporization, and thermal conductivity, were determined before measuring and analyzing the diameters of bubbles. The salts used in this study were sodium chloride and sodium sulfate because these salts result in relatively small de-sedimentation as the electrolyte on the surface of the heater [9].

In models and in previous studies, surface tension was found to be a very important factor in the boiling process. The images of bubble growth in pure water in the presence of sodium sulfate and sodium chloride at a heat flux of $17.356 \mathrm{~kW} . \mathrm{m}^{-2}$ were examined to investigate the impact of surface tension. The addition of impurities to 

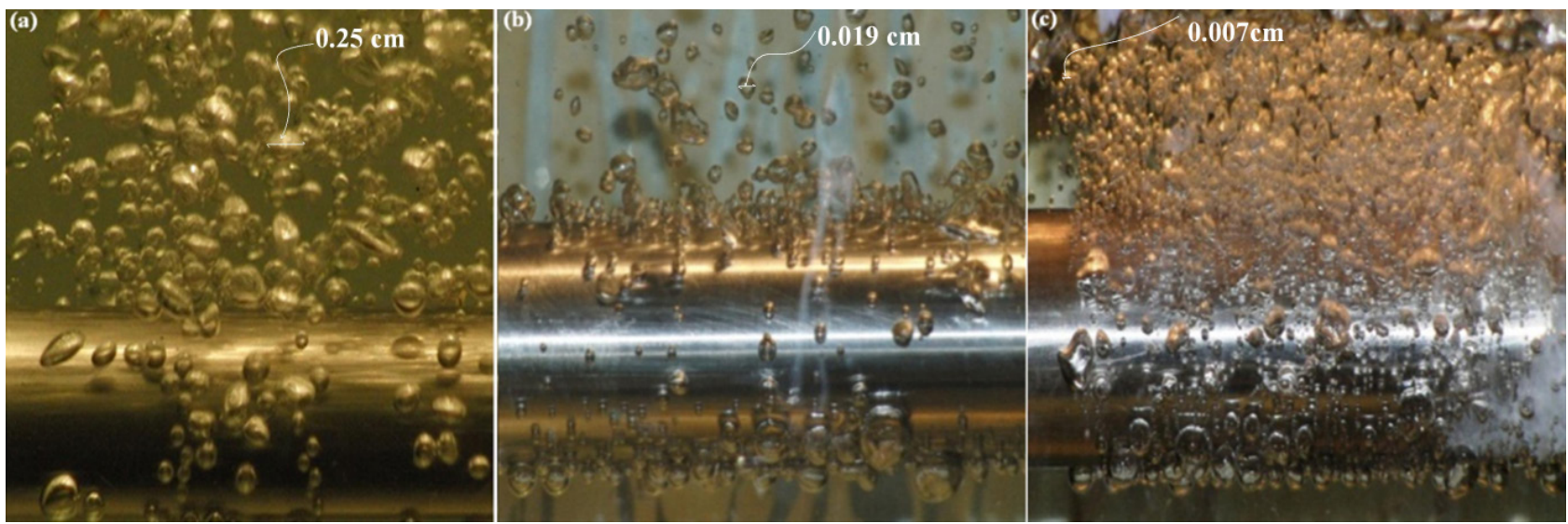

Figure 2: Boiling in a) pure water, b) in the presence of sodium sulfate, and c) in the presence of sodium chloride at a heat flux of $17.356 \mathrm{~kW} \cdot \mathrm{m}^{-2}$.

the water correlates with a decrease in bubble diameter and an increase in cohesion. According to the physical properties of solutions as described in the literature, the surface tension of a water-ethanol solution is lower than that of pure water [10]. Figure 2 provides the images of bubbles with different diameters created in pure water and in solutions containing the salts sodium sulfate and sodium chloride.

Ethical approval: The conducted research is not related to either human or animal use.

\section{Results and discussion}

During thermal movement accompanying natural convection, the wall temperature rises due to increasing heat flux. The first bubbles (nuclei) are formed in the small holes on the rod heater surface in the temperature range of 5 to $30^{\circ} \mathrm{C}$. The bubble departure process begins at $87^{\circ} \mathrm{C}$ and the boiling process begins around the central heater at $100^{\circ} \mathrm{C}$. The system is maintained until it reaches stability within $10 \mathrm{~min}$, after which the central heater is inserted.

In this study, the bubble formation steps were conducted first for pure water, then water-ethanol solutions were prepared at concentrations of 3\%, $7 \%$, and $12 \%$ by volume, and the test was repeated as for pure water. The control of saturation temperature and concentration are more important to the analysis of waterethanol solutions than of pure water. After completion of all the tests, images of 20 bubbles in each heat flux were selected, and the bubble diameters were measured individually with EDIUS software. Afterwards, the average bubble diameter in each heat flux was determined.
For most pure liquids, at least one saturated liquid phase density is experimentally available. The saturation density can be calculated using a modification of Rocket's equation (Equation (1)) [11].

$$
\rho_{l}=\frac{P_{c}}{\operatorname{RT}_{\mathrm{c}} \mathrm{Z}_{R A}\left[1+\left[1-\mathrm{T}_{\mathrm{r}}\right]^{2 / 7}\right]}
$$

where $P_{c}$ is the critical pressure, $\mathrm{R}$ is the general constant for gases, $T_{c}$ is the critical temperature, $Z_{R A}$ is the constant defined by experimental data [11], and $T_{r}$ is the reduced temperature. The liquid phase density in relation to temperature was obtained given the experimental data of part of (a) in Figure 3. All tests were conducted at atmospheric pressure. At this pressure, the vapor can be assumed to be completely in the gas phase; therefore, the density of pure components were calculated with equation (2) [11].

$$
\rho_{v}=\frac{P M_{W}}{R T}
$$

Since most of the resultant vapor originates from the boiling water, the vapor density can be approximated to that of water vapor $\left(\rho_{\mathrm{v}}=598.05 \mathrm{~kg} / \mathrm{m}^{3}\right)$. Figure $3 \mathrm{~b}$ displays the experimentally determined vapor densities. One important factor in bubble dynamics is the liquid surface tension. This parameter is present in almost all predictive equations of the bubble departure and diameter. The equation for surface tension versus temperature is presented as equation (3):

$$
\sigma=a-b \theta
$$



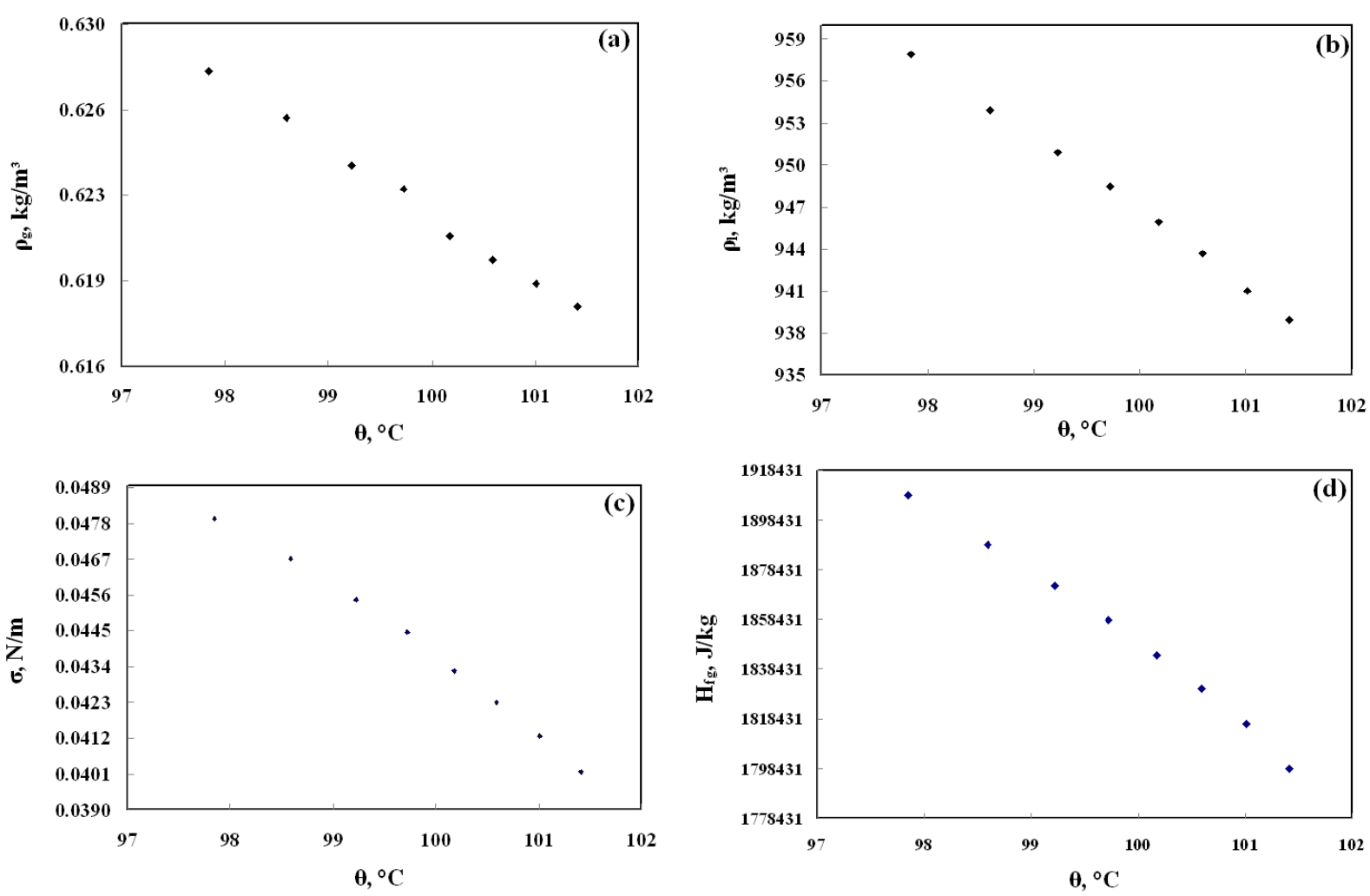

Figure 3: The amounts of a) liquid density, b) vapor density, c) surface tension, and d) vaporization enthalpy of water-ethanol solution (3\% by volume) at different temperatures.

Where $\theta$ is temperature $\left({ }^{\circ} \mathrm{C}\right)$ and $\sigma$ is surface tension $(\mathrm{N} / \mathrm{m})$, the $a$ and $b$ constants are different for various materials and have been determined for a variety of pure liquids. It is necessary to use equations in order to measure this parameter for water-ethanol solutions to calculate the surface tension in the experiments carried out. The surface tension of such solutions is not a simple function of the solution components, because the solution composition is different at the air interface as compared to the composition within the bulk liquid. Prediction of the surface tension of aqueous solutions is far more difficult than non-aqueous solutions due to the nonlinear dependence on the molar components. Very low concentrations of organic matter can significantly affect the surface tension values of aqueous solutions. The following equation is used for aqueous-organic solutions:

$$
\sigma_{m i x}{ }^{1 / 4}=\psi_{w} \sigma_{w}{ }^{1 / 4}+\psi_{0} \sigma_{0}{ }^{1 / 4}
$$

where $\sigma_{\text {mix }}$ is the surface tension of an aqueous solution, $\sigma_{w}$ is the surface tension of pure water, $\sigma_{0}$ is the surface tension of a pure organic composition. The factor $\psi_{\mathrm{w}}$ is defined by equation (5): $\log \frac{\left(\psi_{w}\right)^{q}}{\left(1-\psi_{w}\right)}=\log \left[\frac{\left(x_{w} v_{w}\right)^{q}}{x_{0} v_{0}}\left(x_{w}+x_{0}\right)^{1-q}\right]+0.441 \frac{q}{T}\left[\frac{\sigma_{0} v_{0} \frac{2}{3}}{9}-\sigma_{w} v_{w}^{\frac{2}{3}}\right]$

where $x_{w}$ is the molar mass of a liquid in the solution, $x_{0}$ is the molar component of pure organic composition in the solution, and $V_{0}$ is the molar volume of the salt. Changes in the surface tension of the water-ethanol mixture are shown in Figure 3c. The specific heat capacity is directly correlated with the enthalpy of formation, which can be obtained for the reduced temperature in the range of 0.6 to 7 using Equation (6) as follows:

$$
\frac{H_{f g}}{R T_{c}}=7.08\left(1-T_{r}\right)^{0.345}+10.95\left(1-T_{r}\right)^{0.456}
$$

The vaporization enthalpy can be calculated for pure liquids (water vapor enthalpy: $2257 \frac{\mathrm{kJ}}{\mathrm{kg}}$ ) as shown for twocomponent water-ethanol solution in Figure $3 \mathrm{~d}$.

In addition to the above parameters, the viscosity of liquids in aqueous solutions with one or more polar component, including organic systems, is obtained as follows: 

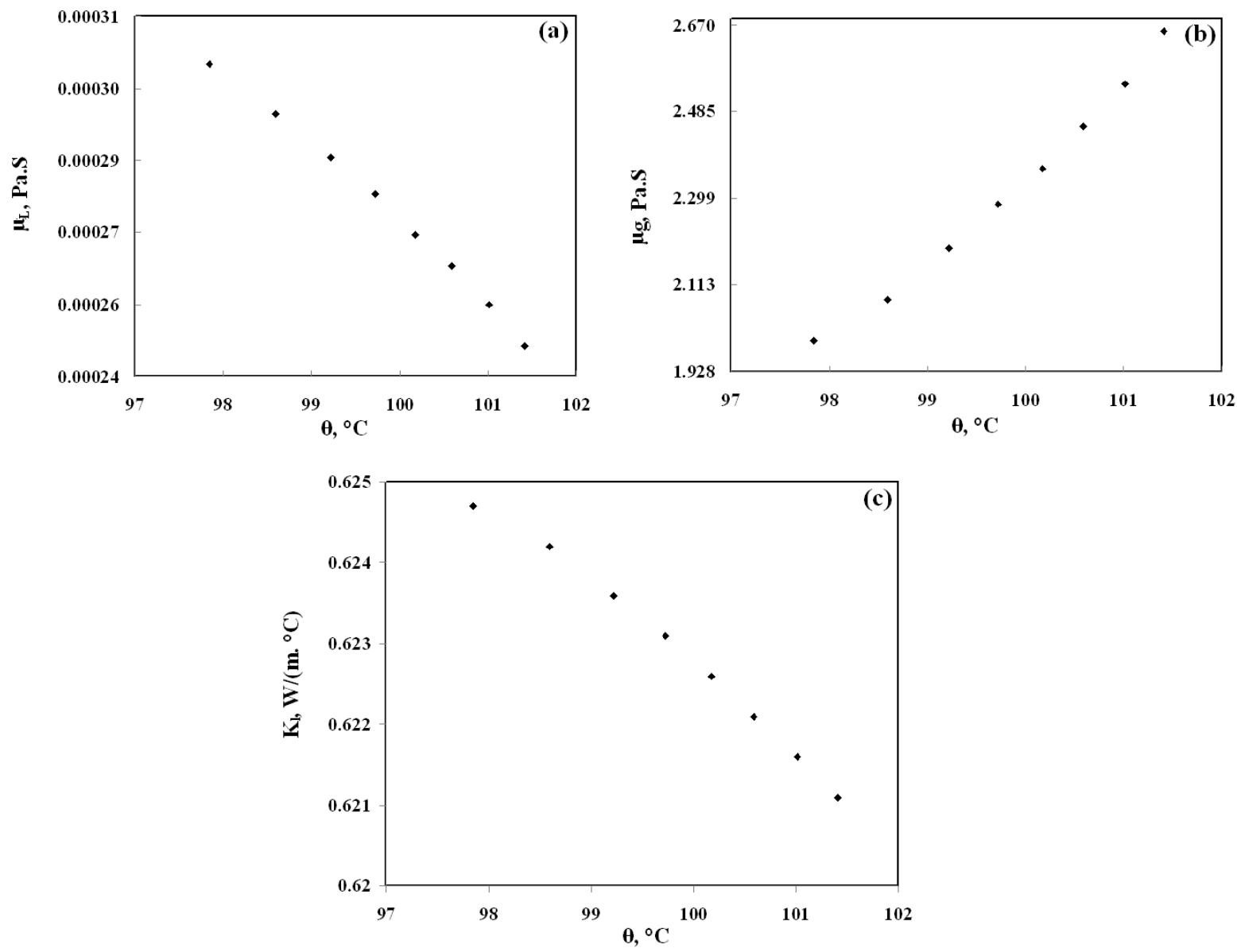

Figure 4: Changes in liquid and vapor viscosities, and thermal conductivity of two-component water-ethanol solution ( $3 \%$ by volume) at different temperatures.

$$
L n \mu_{L, m i x}=X_{1} L n \mu_{11}+X_{2} L n \mu_{12}+2 X_{1} X_{2} G_{12}
$$

In equation (7), $G_{12}$ represents the regulated parameter, which is measured using experimental data from a variety of systems [12], and $\mathrm{X}$ is the liquid molar fraction with an error of about $15 \%$. Figure (3) displays the experimental data on the viscosities of the liquid and vapor tested.

The thermal conductivity of most organic liquids is the range of $0.25-0.4\left(\frac{w}{m . k}\right)$ at a temperature below the boiling temperature. Highly polar liquids such as water have thermal conductivities two or three times the above amounts. The temperature dependence of the thermal conductivity in weak electrolytes has the reverse ratio. The equation is summarized for two-component systems as follows:

$$
K_{l, m i x}=\phi_{1}{ }^{2} k_{l 1}+2 \phi_{1} \phi_{2}+\phi_{2}{ }^{2}
$$

$$
\phi_{i}=\frac{x_{i} v_{i}}{\sum x_{k} v_{k}}
$$

In the above equations, $x_{i}$ is the molar fraction of component $i$, and $V_{i}$ is the molar volume of pure component $i$. The accuracy and computational error of the above equation is not more than $4 \%$.

Figure 4 depicts the thermal conductivity of a two-component water-ethanol solution at various temperatures. Figure 4 indicates that an increase in temperature reduces the viscosity of a liquid and in return increases vapor viscosity. The thermal conductivity of a mixture decreases with increasing temperature.

In the evaluation of the boiling process, the growing bubble diameter was examined for the two-component water-ethanol solution at concentrations of 3, 7, and $12 \%$ by volume at an experimental heat flux of 1.8 to $60 \mathrm{~kW} /$ $\mathrm{m}^{2}$. Different heat fluxes were tested in the water-ethanol system followed by the determination of the surface 

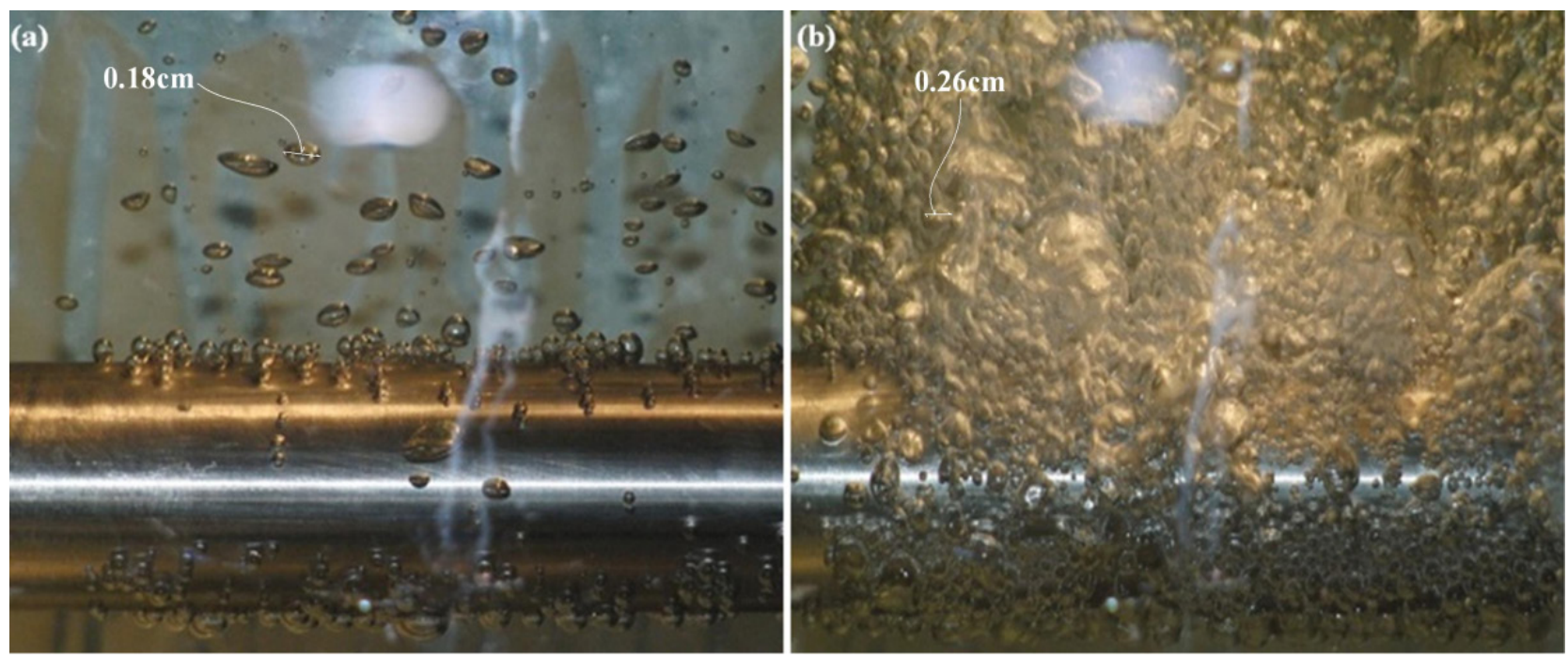

Figure 5: A view of bubble growth in two-component water-ethanol solution at a) low and b) high heat fluxes.

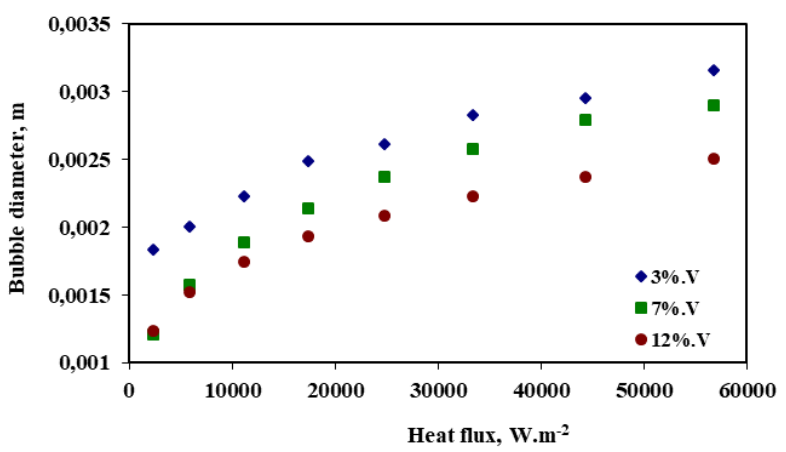

Figure 6: Bubble diameter measured for water-ethanol solution in different heat fluxes.

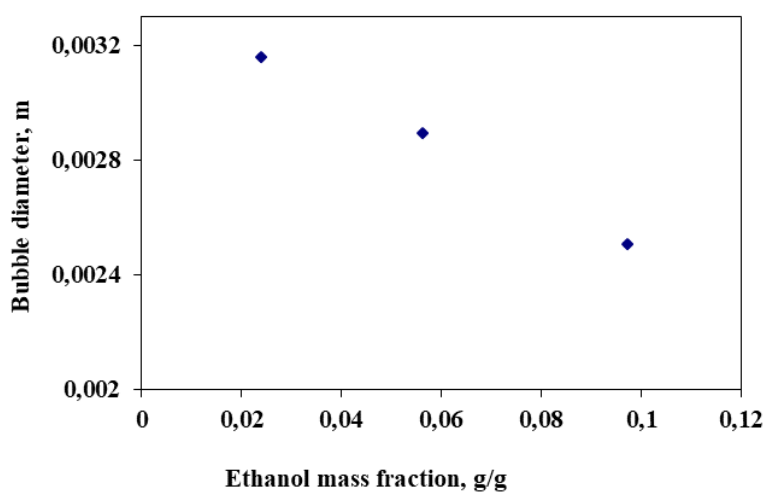

Figure 7: Changes in the bubble diameter by mixing different volumes of water-ethanol solution. and internal tank temperatures. After reviewing and analyzing the images taken during bubble growth (Fig. 5), bubble diameter was measured in each heat flux and density condition. Figure 5 indicates that bubble diameter increased with rising heat flux, suggesting high bubble cohesion at a high heat flux.

Evaluation of the impact of heat flux was repeated for all three concentrations (3, 7, and $12 \%$ by volume) of water-ethanol solution, and their changes are shown in Figure 6 . The bubble diameter increased with increasing heat flux. This correlation is likely due to the increased liquid mixing with rising heat flux.

Experiments dealing with the boiling process of water-ethanol solutions were also carried out at different concentrations to determine the effect of concentration alongside heat flux on the bubble diameter with further precision. It is known that the higher the percentage of impurities in a solution, the higher the heat required to reach the boiling point. As shown in Figure 7, increasing ethanol concentration correlates with reduced bubble diameter in the solution with heat flux of $56715.18 \mathrm{~W}^{\mathrm{m}} \mathrm{m}^{2}$.

A model proposed by Alavi Fazel [11,12] was used to evaluate the diameter of the bubbles as follows:

$$
D_{b}=M N_{C a}{ }^{n}\left(\frac{\sigma}{g\left(\rho_{l}-\rho_{v}\right)}\right)^{0.5}
$$


Table 1: The absolute average error (A.A.E) evaluation by the theoretical models for different volumetric percentage of water-ethanol solution at various heat fluxes.

\begin{tabular}{|c|c|c|c|c|c|c|}
\hline \multicolumn{6}{|l|}{ A.A.E\% } & \multirow{3}{*}{$\begin{array}{l}\text { Heat flux } \\
-\left(W \cdot m^{-2}\right)\end{array}$} \\
\hline \multicolumn{2}{|l|}{$12 \% . V$} & \multicolumn{2}{|l|}{$7 \% . V$} & \multicolumn{2}{|l|}{$3 \% . V$} & \\
\hline $\begin{array}{l}\text { Hamzehkhani } \\
\text { model }\end{array}$ & $\begin{array}{l}\text { Alavi Fazel } \\
\text { model }\end{array}$ & $\begin{array}{l}\text { Hamzehkhani } \\
\text { model }\end{array}$ & $\begin{array}{l}\text { Alavi Fazel } \\
\text { model }\end{array}$ & $\begin{array}{l}\text { Hamzehkhani } \\
\text { model }\end{array}$ & $\begin{array}{l}\text { Alavi Fazel } \\
\text { model }\end{array}$ & \\
\hline 24.20 & 48.02 & 24.80 & 46.80 & 20.70 & 65.07 & 2352.95 \\
\hline 19.70 & 42.30 & $19: 05$ & 44.40 & 14.90 & 56.50 & 5928.20 \\
\hline 17.10 & 38.10 & 15.90 & 42.70 & $14: 50$ & 51.65 & 11184.14 \\
\hline 15.50 & 35.06 & $14: 02$ & 41.50 & 14.90 & 49.90 & 17356.80 \\
\hline 14.30 & 32.40 & 12.60 & 40.50 & 14.60 & 46.40 & 24751.78 \\
\hline 13.40 & 30.10 & 11.60 & 39.60 & $13: 30$ & 45.30 & 33369.06 \\
\hline 12.60 & 27.90 & 10.70 & 38.80 & $13: 07$ & 42.40 & 44278.18 \\
\hline 11.90 & 25.90 & 10.30 & 35.90 & 14.90 & 41.40 & 56715.18 \\
\hline
\end{tabular}

where $D_{b}$, is bubble diameter $(m), M$ is molecular weight $\left(\mathrm{g} \mathrm{mol}^{-1}\right), \mathrm{N}_{\text {ca }}$ is the dimensionless capillary number, $g$ is gravity $\left(\mathrm{m} \mathrm{s}^{-2}\right), \mathrm{n}$ is total mass flux, and $\sigma$ is surface tension $\left(\mathrm{N} . \mathrm{m}^{-1}\right)$. In addition, bubble diameter was calculated using a model proposed by Hamzeh Khani [2] as follows:

$$
B o=C a^{a} A r^{b} J a^{c}
$$

where $B o$ is the dimensionless bond number, $\mathrm{Ca}$ is capillary number, $\mathrm{Ja}$ the dimensionless Jacob number, and $A r$ is Archimedes number. After adjusting the data, the values obtained were: $\mathrm{a}=0.18089, \mathrm{~b}=0.02052$, and $\mathrm{c}=0.55811$. The results of comparing the two theoretical models for different volume composition of the waterethanol solution against heat flux are shown in Table 2. The absolute average error (A.A.E) and experimental diameter $\left(D_{\text {exp }}\right)$ with its computed diameter $\left(D_{c a l}\right)$ are calculated by Eq. (11) to evaluate the model used:

$$
A \cdot A \cdot E \%=\left|\frac{D_{c a l}-D_{\text {exp }}}{D_{\text {exp }}}\right| \times 100
$$

Table 1 shows, with increasing heat flux, the absolute average error decreases. The comparison of the two theoretical models used reveals that the A.A.E\% is lower in Hamzehkhani's model indicating that the two-component water-ethanol solution follows this dynamic model, its lowest error (A.A.E\%=10.30) is in composition of $7 \%$ and for Alavi Fazel model is in 12\%.V (A.A.E\%=25.90).

\section{Conclusion}

This study investigated bubble diameter at heat fluxes ranging from 1.8 to $60 \mathrm{~kW} \cdot \mathrm{m}^{-2}$. The results show that bubble diameter is increased with rising heat flux due to mixing and homogenization of the solution. Increasing the temperature decreases the concentration and density of the liquid phase resulting in elevated heat flux, more heat transfer to the liquid in contact with the metal cylinder, and, ultimately, increased bubble diameter and reduced liquid phase viscosity. The surface tension changed with increasing of solute concentration, and data of the presented theoretical models at composition of $7 \%$ have fitting with the experimental results. Furthermore, most dynamic models for bubble growth become divergent with rising concentration.

Acknowledgment: I would like to thank Islamic Azad University Doroud branch, for providing me with all the necessary facilities for this research.

Conflict of interest: Authors declare no conflict of interest.

\section{References}

[1] Yan L., Li H., Li L., Wu C., Bubble behavior of flow boiling in horizontal rectangular channels with inclined ribs, Int. J. Heat Mass Transfer., 2014, 75, 514-522. 
[2] Hamzekhani S., Maniavi Falahieh M, Akbari A,. Bubble departure diameter in nucleate pool boiling at saturation: Pure liquids and binary mixtures. Int. J. Refrig., 214, 46, 50-58.

[3] Zhang Y., Wei J, Xue Y, Kong X, Zhao J,. Bubble dynamics in nucleate pool boiling on micro-pin-finned surfaces in microgravity. Appl. Therm. Eng., 2014, 70, 172-182.

[4] Jiang Y.Y., Osada H., Inagaki M., Horinouchi N., Dynamic modeling on bubble growth, detachment and heat transfer for hybrid-scheme computations of nucleate boiling. Int. J. Heat Mass Transfer., 2013, 56, 640-652.

[5] McHale J.P., Garimella S.V., Bubble nucleation characteristics in pool boiling of a wetting liquid on smooth and rough surfaces. Int. J.Multiphase Flow., 2010, 36, 249-260.

[6] Golobic I., Petkovsek J., Kenning D.B.R., Bubble growth and horizontal coalescence in saturated pool boiling on a titanium foil, investigated by high-speed IR thermography. Int. J. Heat Mass Transfer., 2012, 55, 1385-1402.

[7] Piorol.L., Rohsenow W., Doerffer S.S., Nucleate pool-boiling heat transfer. II: assessment of prediction methods. Int. J. Heat Mass Transfer., 2004, 47, 5045-5057.

[8] Shoji M,. Studies of boiling chaos: a review. Int. J. Heat Mass Transfer., 2004, 47,1105-1128.

[9] Alavi Fazel, S.A., Shafaee, S.B., Bubble dynamics for nucleate pool boiling of electrolyte solutions. ASME. J. Heat.Transf. 2010, 132 (8), 825021e825027.

[10] Perry R.H, Green, D.W. Perrys chemical engineering handbook, $7^{\text {th }}$ ed, McGraw-Hill, New york, 1997, $3^{\text {rd }}, 273-3.274$.

[11] Alavi Fazel, S.A., Jamialahmadi, M., Semi-empirical modeling of pool boiling heat transfer in binary mixtures I. J.Heat. Fluid Flow. 2013, 44, 468e477.

[12] Alavi Fazel, S.A., Mahboobpour, M., 2013. Pool boiling heat transfer in monoethyleneglycol aqueous solutions. Exp.Therm. Fluid Sci. 2013, 48, 177e183. 